\title{
Research on the Construction of Craftsman Spirit Cultivation Scheme for Mechanical and Electrical Profession
}

\author{
Qian Lv, Yanyan Cao, Li Li \\ Binzhou Polytechnic \\ Binzhou, China
}

\begin{abstract}
In order to satisfy the demand of high-level technical personnel with Craftsman Spirit against the backdrop of Intelligent Manufacturing, this paper studies the construction of craftsman spirit cultivation scheme for students major in mechanical and electrical profession. It takes the Craftsman Spirit as the orientation to optimize the training objectives of mechanical and electrical specialty. Based on the spirit, carry out the talent training model with school-enterprise integration. Finally, it puts forward four talent cultivation systems integrating craftsman spirit, that is, subject teaching system, practice teaching system, culture and professional quality system and innovation and entrepreneurship system. In a word, this paper constructs originally a training mode for mechanical and electrical talents with Craftsman Spirit. Students cultivated by the training mode are more persistent and meticulous in treating technical skills than previous students. Practice has proved that the program has achieved the goal of cultivating high level technical talents who are major in mechanical and electrical engineering and are keep improving and seeking technological innovations.
\end{abstract}

Keywords-Craftsman Spirit; mechanical and electrical profession; cultivation scheme

\section{INTRODUCTION}

Craftsman Spirit refers to the pursuit of perfection, and people with it view technology as the crafts, respect the objective laws while bold to make innovations and embrace changes and strive to become the expert in the field.

Made in China 2025 has proposed that China should shift itself from a manufacturing power to a strong one with high quality as the orientation. Enterprises should possess the consciousness for the best to survive and grow. Craftsman Spirit, the pursuit for perfection can guarantee the quality and the brand. To this end, it is imperative to produce technical personnel with Craftsman Spirit who pay meticulous attention to details in the manufacturing of a product, so as to allow products made in China go to the wider world.[1]

As far as the Craftsman Spirit is concerned, it aims to realize the localization and production of core technologies and core components, which requires the motivation of scientific development and the goal of intelligent technology. Among the five projects of Made in China strategy, intelligent manufacturing, manufacturing innovation center construction and high-end equipment innovation are highlighted. With the

This paper is supported by the teaching research topic of Binzhou Polytechnic in 2017, "Research and Practice of Innovative Talent Cultivation Mode of School-Enterprise Penetration, Gradual Progress and Multi-Track Parallel of Electromechanical Professional Group” remarkable development of intelligent manufacturing, intelligent control becomes an important development direction of the mechatronics technology. As industrial robots, intelligent production line and intelligent control technology has become the development trend of enterprise technology upgrades, adjacent enterprises urgently need a lot of specialized talents to maintain and upgrade intelligent mechanical and electrical equipment.

Therefore, the mechatronics major assumes the social responsibility to cultivate high-level technical, skilled talents with the spirit of "keep improving and scientific and technological innovation". This paper discusses the construction and implementation of the cultivation program of the Craftsman Spirit of mechatronics profession.

\section{TAKING CRAFTSMAN SPIRIT AS THE GUIDANCE TO OPTIMIZE THE GOAL OF TALENT TRAINING}

Taking Craftsman Spirit as the orientation, mechanical and electrical profession is optimized in terms of the training objective and professional scope.

\section{A. Training objective}

Take the Craftsman Spirit cultivation as the essence of education, and as the primary objective of vocational education. Infiltrate the Craftsman Spirit cultivation into process of professional talents training. Alongside the professional skill training, we should teach students to be patient, responsible, and meticulous, whole-hearted, dedicated, keep improving, and forming the Craftsman Spirit. In this way, the technical talents requirements amid the transformation of "Made in China" can be satisfied. Students graduated from polytechnics can all find the appropriate jobs, thus promoting the sustainable development of vocational education.

\section{B. Professional scope}

The profession mainly focuses on local intelligent manufacturing, based on intelligent control technology on the new professional, serves intelligent control equipment manufacturing and application service, at the same time, adjusts the professional post for mechatronics technology, and with industrial robots, intelligent industrial control system as the core, educates innovative, developmental, and technical skills talents that understand the principle, can adjust, repair, and process design and programming. 


\section{Practice The SChOOL-ENTERPRise InTEgRATED TALENT} TRAINING MODEL BASED ON THE CRAFTSMAN SPIRIT

The Craftsman Spirit cannot be obtained without the accumulation of work practice and the edification of enterprise culture. Therefore, mechatronics specialty relies on the integration of teaching and production and the cooperation of school and enterprises to cultivate vocational college students' Craftsman Spirit.

While training technical talents to obtain craftsman spirit, we should give full play to modern apprenticeship, and build a school-enterprise cooperative education mechanism with school-enterprise integrated personnel training mode as the core.

\section{A. Innovating the mode of "school-enterprise infiltration and progressive talent cultivation"}

We should stick to the unity of knowing and doing, combining learning with working, keep exploring and deepening the phased talent training mode with participation of the school and enterprises.

The combination of learning and working and phased teaching are realized in both competence cultivation and school-enterprise cooperation. As for the competence cultivation, various teaching modules of ordinary and practical teaching are organized flexibly. We regard to school-enterprise cooperation, such activities in universities as general vocational ability training, basic skills training, comprehensive ability training, ability training for different professional orientation, project research and development coordinate with those practices in enterprises like cognition practice, post internship, taking post to practice, internship before employment.

In the integration of theory and practice, research and development center and production workshop, students can work and study at the same time. Knowledge and action go hand in hand in accordance with the patter that working and learning alternates, then closely interconnected, mutual penetrate and fully integrated with each other. Their skill improves from the professional basis, professional core, professional development, job skills. In this way, the personnel training mode that is characterized by the penetration of school and enterprise, and the phased development is formed, promoting cultivation of technical talents with Craftsman Spirit.

B. Building a modern apprenticeship system school-

enterprise alliance, integrated education, alternation of

learning and training, and post internship

Mechatronics specialty is the pilot project of modern apprenticeship in Shandong Vocational education. The pilot class, on the basis of the above personnel training mode, tries to grasp the apprenticeship opportunities to join hands with Wanda group to determine the knowledge, ability and quality of the talents required by their tire manufacturing jobs. In this way, we can launch the talent training mode with characteristic of apprenticeships, cooperation of universities and enterprises, and phased development.

In a production-centered enterprise, senior technicians with rich production experience should be given full play to guide students to form a mentoring relationship during their internship. Students should follow the technical requirements of their master to operate and produce. Through the positive interaction between masters and students, students will be influenced by the spirit of craftsmanship subtly.

\section{INTEGRATE THE CRAFTSMAN SPIRIT TO BUILD A TALENT CULTIVATION SYSTEM}

A. The core: "Craftsman Spirit" is integrated into the discipline teaching system of "broad basic platform + flexible post module"

Subject teaching is one of the core contents of higher vocational education. Implanting craftsman spirit subtly in students' mind to let students grasp its connotation by integrating craftsman spirit into the subject teaching system and introducing it into daily teaching is what craftsman spirit cultivation should do essentially.

Mechatronics specialty focuses on the requirements of intelligent manufacturing and a powerful country of quality, determines the key professional skills and qualities for professionals, and based on that, reconstructive the curriculum system. With professional quality cultivation as the main line, build the platform for "craftsman spirit" education, forming a teaching system with broad basic platform and flexible post module.

\section{1) Broad basic platform}

The broad basic platform provides students major in mechatronics with shared courses of basic quality and professional ability, laying a foundation for cultivating complex and developmental talents with craftsman spirit.

The spirit of craftsman is integrated into the teaching process. Teachers teach students professional knowledge and let them understand the connotation of "craftsman spirit" of "keep improving and pursue excellence" by setting an example themselves and strict teaching objectives, so as to cultivate students' professional belief of “craftsman spirit”.

\section{2) Flexible post module}

In order to adapt to the development of intelligent manufacturing, flexible job modules that mainly train students' occupation ability and professional quality, include professional core course, professional direction guidance, project research and development course, elective course and extracurricular credit.

Major core curriculum module aims to train students to master the key technical skills of mechanical and electrical equipment.

In the professional direction module, the electromechanical major is set in two directions, that is, industrial robot and intelligent production line, so as to facilitate students accumulate necessary professional skills for cultivating "craftsman spirit”.

The course module of project research and development is provided for students to participate in research and development through enterprise projects, scientific research patent projects and competitions, aiming to improve students' innovative research and development ability of intelligent products and intelligent systems. In the projects, students can 
experience the working situation of the enterprise, realize the "constant innovation and study" in the "Craftsman Spirit", and grow as innovative technical talents.

In the specialized elective course module, students can acquire professional knowledge and explore related professional fields, and become interdisciplinary talents of electromechanical and intelligent control. This can not only open up innovative fields and also cultivate innovative talents.

Extracurricular credit module is also known as the second classroom. Students can take part in community activities such as robot association, innovative BBS activities such as intelligent Internet of things, and skills competitions such as embedded system development and acquire vocational qualifications such as maintenance electrician, to obtain credits. All these can improve students' professional development ability and social ability and internalize their "craftsman spirit".

\section{B. The focus: "Craftsman Spirit" runs through the "progressive stage + dual-track parallel” practical teaching system}

Professional training is an important means to cultivate craftsman spirit. Based on the Craftsman Spirit, the emphasis is to further improve the school-enterprise cooperation mechanism and modern apprenticeship system, and to create a practical teaching system of working and learning alternation [2].

Mechanical and electrical specialty takes the cultivate of Craftsman Spirit as the mainline, gradually improve students' basic skills, special ability, comprehensive ability, post ability, scientifically set training practice content. The teaching practice should be set as a separate teaching system which contains the professional general ability training, professional basic ability training, professional comprehensive ability training and professional direction ability training on campus and cognition practice, post internship, taking post to practice, internship before employment off-campus , which promotes students' phased accomplishment in craftsman skills and quality. In practical teaching, integrate "craftsman spirit” into professional course and practical training, so as to organically combine "Craftsman Spirit" with technical activities and skills cultivation. Let students experience and develop Craftsman Spirit in practice.

\section{The support: creating a cultural and professional quality system with "Craftsman Spirit"}

The establishment of craftsman cultivation system needs to be based on the support of craftsmanship culture, integrate industrial culture and "Craftsman Spirit" [3], so as to construct a curriculum system of cultural and professional literacy cultivation. With the cultivation of professional concept as the main line, professional cultural quality and professional humanistic quality as the core, the culture of production, industry, enterprise and occupation is integrated into the talent training, and the "craftsman spirit" is penetrated into professional courses and practical training, so as to enable students experience the professional culture and the craftsmanship in practice.

\section{1) Building the campus culture of craftsman}

Debates and speeches on the values of dedication, persistence and pursuit of perfection can be held regularly to promote the spirit of craftsmanship. Experts in Marxism and Leninism, model workers and outstanding graduates can be invited to give lectures on "craftsman spirit". It is also viable to carry out knowledge quiz and speech contest, vocational skills competition, and publicize through campus display board, slogan culture, etc.

2) Strengthening the main role of ideological and political education

According to the cognitive and behavior characteristics of college students, Craftsman Spirit can be introduced into the teaching of employment concept and professional virtues [4], so that students can master the connotation of the spirit, improve comprehensively ideological and political quality and professional quality.

\section{3) Strengthening vocational quality education}

Firstly, professional education should be strengthened in combination with professional characteristics, and professional awareness should be enhanced through enterprise internship and other activities, so as to help students form professional attitudes and ethics that respect profession, love profession, cherish work and fulfill their duties.

Secondly, the vocational condition should be fully connected in the management of experimental training room and student dormitory, and the standardized $6 \mathrm{~S}$ management should be implemented.

Finally, in professional teaching, teachers do not take the "done" but the "perfect" as the standard, and strictly follow the procedures and standards of operation, training students to be precise and accurate craftsmen.

\section{4) Professional course of "craftsman spirit" education}

The professional course of "craftsman spirit" education can be introduced into the curriculum system of mechatronics specialty. When formulating the talent training plan, "craftsman spirit" should be set up separately with certain class hours [5]. Set the education curriculum with the Craftsman Spirit as the core, with skillful craftsmen's story as the carrier, through the interpretation of the documentary film "Artisans of China”, train students to perceive, understand the spirit of craftsmanship ability, stimulate students to practice the spirit consciously, so as to lay a solid foundation for the formation of students' vocational skills and professional quality.

\section{5) Social practice activity of "Craftsman Spirit"}

In combination with local characteristics, such social practices can be organized as visiting model workers' bases and on-site teaching by model workers to learn the "spirit of craftsmen" of bearing hardships and working hard. Lead students to visit the industrial museum, so that students can understand China's industrial development, and enhance the sense of responsibility and honor of being a craftsman in a big country. Organizing students to visit Yangliuxue town to learn the persistence of working under and hard conditions and "hard work and skillful work". Experiencing themselves the "Craftsman Spirit" can not only promote the industrial development, but also have important significance to the 
construction of new countryside, and then help them understand the social value and importance of the craftsman spirit.

6) Rigorous and diligent school spirit and discipline

Forge the rigorous and diligent school spirit and discipline [6], establish the rigorous work atmosphere and the spirit of diligent study. In this circumstance, students dare not be careless in learning and operation. Over the years, the students gradually develop the good habit of working conscientiously and responsibly and the spirit of craftsman.

\section{The deepening: the spirit of craftsmanship is incorporated} into the innovation and entrepreneurship system

Establish the specialized courses to guide innovation, course to open creative thinking and frontier lecture to expand innovation areas, special project to practice innovation ability, and release policies and measures to support innovation entrepreneurship. All these innovation entrepreneurship education methods can improve the level of students' innovative quality and help explore and carry forward the connotation of the Craftsman Spirit in innovation and entrepreneurship.

Drawing from the experience of "teaching factory" of Nanyang Technological University, we can launch cooperation with China Wanda group, Binzhou Piston group and Weiqiao aluminum electric co., LTD., to establish R\&D center and innovation platform that are similar to the enterprise practice place. Project research and development practice can be carried out after two years of basic mechanical and electrical professional education. Students participated in that will be guided the teacher, also engineer who takes charge of the project, to research and develop enterprise project, scientific research patent project or competition project. In this way, students can apply what they have learnt to diversified and multi-level working conditions. Through the project, the new technologies of the school and the enterprise will be deeply integrated, so that the content of talent training will be synchronized with the new technologies of the enterprise, and teachers will be trained to become $R \& D$ masters, forming a virtuous circle of "project promotes master, master leads project”. It is necessary to focus on improving the innovative
R\&D ability of students and cultivate innovative technical talents.

\section{CONCLUSION}

This paper adheres to the national development strategies like building a powerful country of quality and intelligent manufacturing, and social demands. A study on the construction of Craftsman Spirit cultivation plan for electromechanics profession was conducted from multiple channels and aspects like "optimizing talent cultivation goal with the spirit of craftsmanship", "Craftsman Spirit-based school-enterprise integrated training mode", and "build a talent cultivation system integrating craftsmen spirit”.

After the introduction of the program, students not only greatly enhance their technical skill levels, but also improve their post adaptability. Having been exposed to the enterprise culture and master's excelsior spirit, they do better that previous generations of students in sense of purpose and responsibility for academic learning, and dedication and meticulous in technology skills. It can be seed that the Craftsman Spirit of "strive for perfection and innovation of science and technology” has been deep rooted into students' mind.

\section{REFERENCES}

[1] Sun Xingyang. Vocational Education Highlighting Craftsman Spirit [N]. People's Daily, 2016-03-24

[2] Meng Yuanbei, Chen Xiaojuan. The Connotation of Craftsman Spirit and the Construction of Cooperative Cultivation Mechanism [J]. Vocational \& Technical Education, 2016 (27):16-20

[3] Yu Caixia.On System of Craftsman Spirit Acquirement by Vocational College Students [J]. Modern Education Management, 2017 (7):232-234

[4] Sun Yang. On the Cultivation of Higher Vocational Students' Craftsman Spirit [J]. Journal of Liaoning Higher Vocational, 2017, (6):7-9.

[5] Wang Xinyu. Research on the Cultivation of Higher Vocational Students' Craftsman Spirit from the Perspective of "Made in China” [J]. Vocational Education Research,2016, (2):14-17

[6] Wang Pengcheng, Huang Wei, Hu Youfeng. Construction of "Craftsman Spirit" Cultivation System in Higher Vocational Colleges [J]. Communication of Vocational Education,2017, (29):20-22 